This item was submitted to Loughborough's Research Repository by the author.

Items in Figshare are protected by copyright, with all rights reserved, unless otherwise indicated.

\title{
"What do you expect from physiotherapy?": a detailed analysis of goal setting in physiotherapy
}

PLEASE CITE THE PUBLISHED VERSION

https://doi.org/10.3109/09638288.2013.867369

\section{PUBLISHER}

(C) Taylor \& Francis

\section{VERSION}

VoR (Version of Record)

\section{PUBLISHER STATEMENT}

This work is made available according to the conditions of the Creative Commons Attribution-NonCommercialNoDerivatives 4.0 International (CC BY-NC-ND 4.0) licence. Full details of this licence are available at: https://creativecommons.org/licenses/by-nc-nd/4.0/

\section{LICENCE}

CC BY-NC-ND 4.0

\section{REPOSITORY RECORD}

Schoeb, Veronika, Liliana Staffoni, Ruth Parry, and Alison Pilnick. 2019. ""what Do You Expect from Physiotherapy?": A Detailed Analysis of Goal Setting in Physiotherapy". figshare. https://hdl.handle.net/2134/32683. 


\title{
"What do you expect from physiotherapy?": a detailed analysis of goal setting in physiotherapy
}

\author{
Veronika Schoeb ${ }^{1}$, Liliana Staffoni ${ }^{1}$, Ruth Parry ${ }^{2}$, and Alison Pilnick ${ }^{3}$ \\ ${ }^{7}$ HESAV - Department of Physiotherapy, University of Applied Sciences, Western Switzerland - HES-SO, Lausanne, Switzerland, ${ }^{2}$ School of Nursing, \\ Midwifery and Physiotherapy, University of Nottingham, Queen's Medical Centre, Nottingham, UK, and Department of Sociology, University of \\ Nottingham, Science Park, Nottingham, UK
}

\begin{abstract}
Purpose: Health care practice guidelines require physiotherapists to include patients in goal-setting. However, not much is known about how this process is accomplished in practice. The purpose of this study is to analyse patient-physiotherapist consultations and to identify how physiotherapists enquire about goals and how patients respond to these enquiries. Method: 37 consenting patients and their physiotherapist from outpatient physiotherapy practice settings were videotaped. Conversation analysis was used to transcribe and analyse the data. Results: In 11 cases, physiotherapists enquire explicitly about goals. Patients' responses indicate that problems can arise when therapists' questions treat it as expected that the patient has a goal already in mind, and has sufficient understanding about "physiotherapy-relevant" goals. Patients' difficulties with stating a goal are related to patients' knowledge to propose a goal and whether they treat consultations as one in which it is appropriate to claim knowledge about goals. Conclusions: Goal-setting is not a straightforward process. Practices that entail asking patients to state their goals neither take into consideration the fact that patients may not know what an achievable goal is nor do they consider so-called social reasons for patients not to make claims to their physiotherapist about what the goals should be.
\end{abstract}

Keywords

Communication, conversation analysis, goal setting, physiotherapy

\section{History}

Received 26 April 2013

Revised 10 November 2013

Accepted 15 November 2013

Published online 11 December 2013

\section{Introduction}

Goal setting theories, developed in industrial North America during the 1950s and 1960s, posit that setting a goal influences human behaviour in such a way that it increases performance and motivation [1]. Theories along this line, e.g. Social Cognitive Theory, Goal Setting Theory and Health Action Process, are adopted by health professions in recent years and are suggested to be incorporated in clinical practice [2]. Goal setting is included as a recommended practice in contemporary clinical guidelines and professional standards of practice [3,4]. One approach regularly advocated is the SMART (Specific, Measurable, Achievable, Realistic and Timed) approach to formulating goals [5]. This approach is intended to enable quantification of patients'

\footnotetext{
Address for correspondence: Veronika Schoeb, HESAV - Department of Physiotherapy, University of Applied Sciences, Western Switzerland - HES-SO, 21 ave Beaumont, 1011 Lausanne, Switzerland. E-mail: veronika.schoeb@hesav.ch
}

performance and of the time in which the desired goal is achieved. Yet, this process has some limitations as patients may not feel competent enough to actively engage in the process, and clinicians may be reluctant to actively engage patients in setting goals if they perceive patients might have limitations in communication and expertise [6].

Evidence is mixed with regard to application of goal setting theories [7,8]. A recent review of qualitative and quantitative studies investigating the effects and experiences of goal setting in stroke rehabilitation identified a number of barriers to goal setting [8]. The authors conclude that participants are often unclear about their role and that there is a lack of understanding of the rehabilitation process. In addition, a discrepancy seems to exist between perception and actual practice with regard to patient participation [8]. It is further suggested that clinician should examine the value attributed to certain types of goals, as well as taking into consideration the organisational drivers influencing the goal selection [7].

In sum, the process of goal setting seems to have limitations. Only a few studies observed in detail the actual practice of goal 
setting and give insight into the complexity of this process $[9,10]$. These latter studies show that - as in any communicative activity - goal setting does not just involve the provision of information (i.e. exchange of goal information). Rather, as we all intuitively recognise, when we communicate about goals we also show to one another: (a) what we assume the other person understands or does not understand, and (b) what we assume we can and cannot appropriately say to one another. In this sense, goal setting needs to be understood as a social action in which goals are shaped through the conversation between a physiotherapist and a patient. Our study, therefore, illuminates differences between the theories of goal setting [1,2], the patients' or professionals' perceptions about this process $[7,8]$ and the actual practice by providing insights into how goals are topicalised in health care interactions.

This article will build on existing observational studies by analysing how physiotherapists initiate goal setting and how patients respond to this enquiry. Findings from medical consultations show that questions are not neutral, and that they do more than seeking information [11]. In fact, questions can also be designed to communicate information to patients and can convey information about setting agendas and epistemic stance (related to knowledge claims); they can also embody presuppositions and incorporate preferences [12]. Health professionals formulate questions in such a way that assumptions about patients' knowledge are recognisable within them. The current article sheds light on problems that occur in some goal setting conversations by unpicking the assumptions embedded in the goal enquiry by physiotherapists, and showing how these assumptions can then be seen to be at the heart of difficulties that patients sometimes exhibit in stating a therapy-relevant goal.

The aim of this observational study is to present different practices of goal enquiry during initial encounters in musculoskeletal physiotherapy in a French speaking context. The purpose is to shed light on how physiotherapists topicalise treatment goals using explicit questions, how patients respond to these enquiries, and why - not infrequently - these goal setting sequences do not go smoothly.

\section{Methods}

Conversation Analysis is an inductive and data-driven approach which seeks "to capture the understandings and orientations displayed by the participants themselves", while enforcing "rigorous standards of evidence made possible by the use of recorded data' (p. 590) [13]. The focus of the investigation is on sequences of communication rather than on individuals' talk and emphasises the co-constructed aspect of communication [14]. Conversation Analysis has become the pre-eminent means of analysing medical communication [15] as well as those amongst other professions, e.g. pharmacy [16], physiotherapy [9] and nursing [17]. One study recently published in this journal and using the same methodology analysed the social interactions between a person with a traumatic brain injury (TBI) and his carer shedding light on instances of touching behaviours commonly occurring in people with TBI [18]. The detailed analysis of healthcare consultations is an especially suitable method for identifying patterns of behaviour as well as communication strategies [19], and the findings it produces can be applied to provide practice recommendations, propose policies or adapt work environments in health care [14]. This systematic approach, however, has been rarely applied to physiotherapy with a few exceptions [9,20,21].

\section{Setting, participants and data collection}

Thirty-seven patients with musculoskeletal problems (e.g. low back pain, knee problems, shoulder pain) referred to an outpatient physiotherapy department of a university hospital or to two private practices - all in French-speaking Switzerland and 12 physiotherapists participated in the study. Conversation Analysis considers any interaction as "worthy of an intense and detailed examination" (p. 51), and no specific sampling techniques are used to select a set of representative cases [22]. However, a description of participants is provided in Tables 1 and 2 for readers to assess the transferability of claims to their own context. For each patient, the first five consultations were video-taped. Physiotherapists used a wireless microphone to give both parties freedom of movement without compromising the sound quality. The video operators were located at the corner of the treatment room and behaved in ways intended to minimise their influence during the session. Ethics committee approval was granted by the local commission and was consistent with the Declaration of Helsinki [23]. Participants signed an informed consent form and confidentiality was guaranteed.

\section{Data analysis}

A detailed systematic analysis of each video-recorded consultation was performed by the first author using the methods of Conversation Analysis [24,25]. The focus was on aspects such as how turns are organised and structured (e.g. the wording and intonation of questions and answers), how sequences were organised (e.g. how goal setting activity starts, continues and closes down), what vocabulary was chosen and whether

Table 1. Background information of patients.

\begin{tabular}{|c|c|c|c|}
\hline $\begin{array}{l}\text { Patients' reasons to } \\
\text { seek physiotherapy }\end{array}$ & Total & $\begin{array}{l}\text { Private } \\
\text { practice }\end{array}$ & $\begin{array}{l}\text { Hospital-based } \\
\text { outpatient } \\
\text { clinic }\end{array}$ \\
\hline Patients with low back pain & 13 & 4 & 9 \\
\hline Patients with knee problems & 11 & 3 & 8 \\
\hline Patients with shoulder pain & 4 & 2 & 2 \\
\hline Patients with ankle problems & 4 & 1 & 3 \\
\hline Patients with hip pain & 2 & 1 & 1 \\
\hline $\begin{array}{l}\text { Patient with cervical } \\
\text { radiculopathy }\end{array}$ & 1 & 1 & 0 \\
\hline $\begin{array}{l}\text { Patient with Parkinson's } \\
\text { disease and hip arthroplasty }\end{array}$ & 1 & 1 & 0 \\
\hline \multirow{2}{*}{$\begin{array}{l}\text { Patient with multiple fractures } \\
\text { after motorcycle accident }\end{array}$} & 1 & 1 & 0 \\
\hline & $\begin{array}{l}37 \text { patients, } \\
\text { aged } 18-82 ; \\
15 \text { male, } \\
22 \text { female }\end{array}$ & 14 patients & 23 patients \\
\hline
\end{tabular}

Table 2. Background information of physiotherapist.

\begin{tabular}{|c|c|c|c|c|}
\hline Code & Site & Sex & Specialisation & Experience \\
\hline PTo & Private practice & Male & Manual therapist & 32 years \\
\hline PTp & & Male & Manual therapist & 25 years \\
\hline PTq & Hospital & Female & All rounder & 5 years \\
\hline PTr & & Female & Paediatric specialist & 10 years \\
\hline PTs & & Female & $\begin{array}{l}\text { Generalist/ } \\
\text { clinical educator }\end{array}$ & 3 years \\
\hline PTt & & Female & Generalist & 7 years \\
\hline PTu & & Female & Novice & $\begin{array}{l}\text { First year } \\
\text { of practice }\end{array}$ \\
\hline PTv & & Female & Generalist & 21 years \\
\hline PTw & & Female & Manual therapist & 6 years \\
\hline PTx & & Male & Student/final year & \\
\hline Pty & & Female & Student/final year & \\
\hline PTz & & Female & Student/final year & \\
\hline
\end{tabular}


asymmetries were observable [24,25]. Sequences related to goal setting were selected (when goals were explicitly discussed or referred to), viewed and transcribed using Jefferson's transcription conventions [26] (see Appendix 1). The analysis focused on how physiotherapists topicalise goals in initial assessment consultations as it is the place where assumptions embedded in questions are the most visible.

The videos once collected were transferred to $\mathrm{ELAN}^{\circledR}$ (Version 4.4.0), a software programme available for the analysis of videos (see Figure 1) and offered for free by the MaxPlank-Institute (http://tla.mpi.nl/tools/tla-tools/elan).

In accordance with conventions for Conversation Analysis, detailed information is transcribed (e.g. who talks, how long, overlap, pause, etc.) in order to describe how participants make sense of each other's talk.

The presentation of the findings includes simplified transcripts of the actual spoken interaction. For the purpose of this article, transcripts are presented using a two-line translation with the first line written in spoken French and the second line in an idiomatic representation of the language [22].

\section{Findings}

Thirty-seven consenting patients and their physiotherapists were videotaped during their five initial consultations, between March 2009 and March 2011. A total of 161 consultations were recorded (93 consultations in the hospital-based outpatient clinic; 68 consultations in private practices) amounting to approximately 90 hours of video recordings; however, only the initial goal setting enquiry was analysed for the purpose of this paper (37 interactions). Table 1 describes the patient population under study and Table 2 the physiotherapist's background.

In 21 of 37 first encounters no explicit goal-setting process was observable. For the remaining 16 cases, there were two different ways of making goals and expectations explicit:

(1) Physiotherapists enquire about patients' goals explicitly using questions like "what do you expect from physiotherapy?", (11 cases), or
(2) Patients present their goals without being asked (5/37).

For this paper, we focus on all cases in which physiotherapists use questions to enquire explicitly about the expectations/goals with regard to physiotherapy (Table 3 ). It is important to understand explicit goal setting practices and to describe how and why communication patterns emerge. Those findings may explain why in $56 \%$ of the consultations, goal setting is not initiated explicitly.

Table 3. Overview of included cases $(N=37)$.

\begin{tabular}{lccc}
\hline \multicolumn{2}{l}{ Explicit goal enquiry $(N=11)$} & & \\
\cline { 1 - 2 } $\begin{array}{l}\text { Straightforward } \\
\text { responses }\end{array}$ & $\begin{array}{c}\text { Not easily } \\
\text { produced responses }\end{array}$ & $\begin{array}{c}\text { Patient-initiated } \\
\text { goals }(N=5)\end{array}$ & $\begin{array}{c}\text { No explicit goal } \\
\text { enquiry }(N=21)\end{array}$ \\
\hline HO 02 & HO 03 & HO 01 & HO 08 \\
HO 11 & HO 04 & HO 06 & HO 09 \\
HO 13 & HO 05 & HO 14 & HO 10 \\
& HO 07 & HO 15 & HO 17 \\
& HO 12 & HO 21 & HO 19 \\
& HO 15 & & HO 20 \\
& HO 18 & & HO 22 \\
& HO 23 & & L 01 \\
& & & L 02 \\
& & & L 03 \\
& & & L 04 \\
& & & R 01 \\
& & & R 02 \\
& & & R 03 \\
3 cases & & & R 05 \\
& & & R 06 \\
& & & R 07 \\
& & & R 09 \\
& & & 21 cases \\
\hline cases & &
\end{tabular}

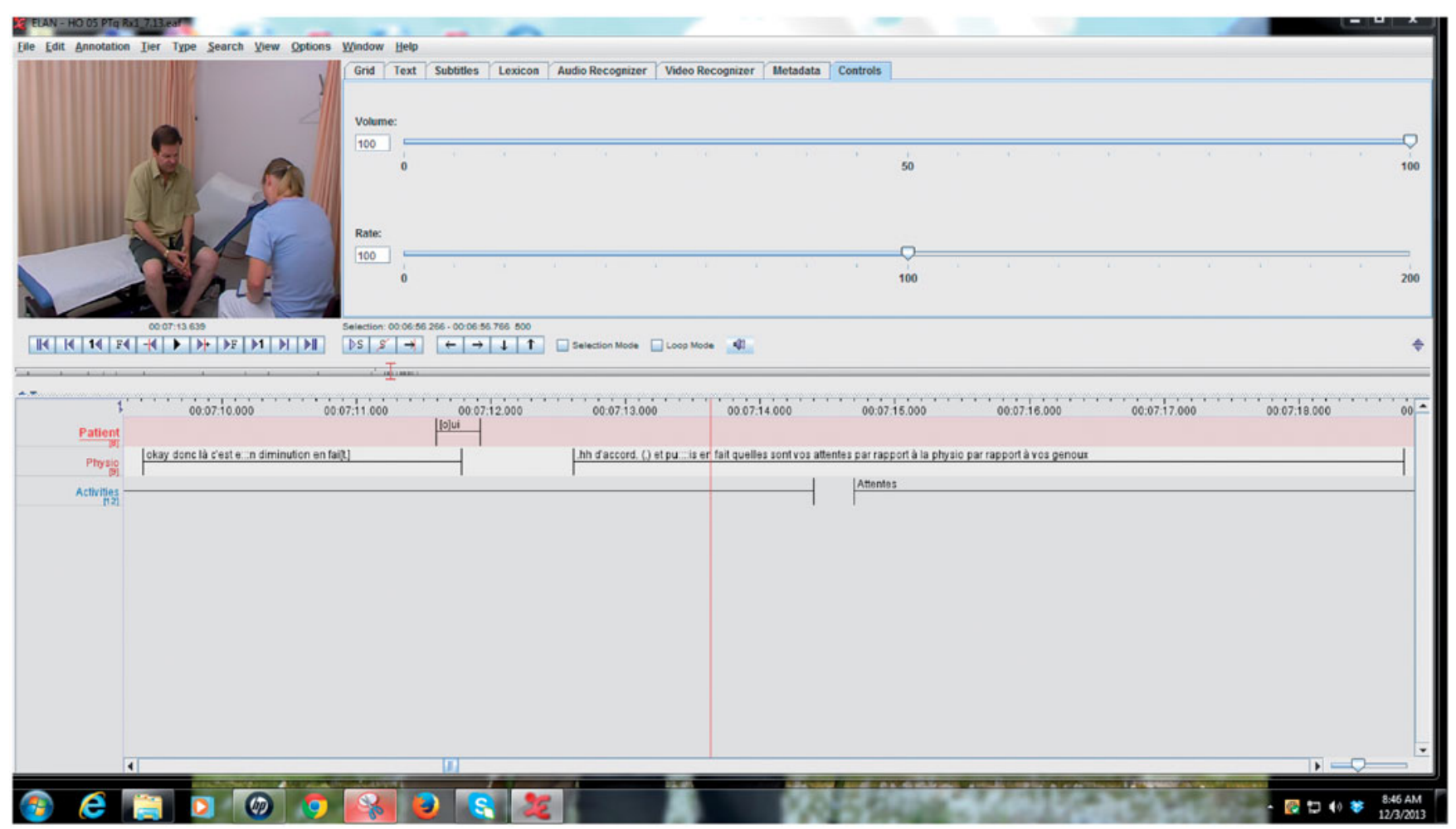

Figure 1. Software programme ELAN $^{\circledR}$ for transcription (Max-Planck-Institute, Nijmergen, NL). 


\section{Explicit enquiry about expectations for physiotherapy treatment}

Our data show that the process of goal setting when enquiring explicitly about goals is not always straightforward. Problems arise as a result of the tension between the assumptions that is embedded in the question - that patients have both a goal in mind and are able to formulate it - and patients' orientation to their knowledge about goals. Patients often moderate their knowledge claim thereby showing their uncertainty with regard to goals.

In the first section, we present some examples to show the way physiotherapists enquire about goals using open questions to initiate the process. In conversation analytic literature, this type of questions is described as wh-question (what, when, how, where, etc.) but for the purpose of this paper, we will call them "open questions". Those questions are introduced after bringing the prior topic to an end and indicate thereby that goal-setting is to be treated as a new topic. We will present evidence showing that those questions embed assumptions about what the patient already knows. In the second section, we examine patients' responses to goal enquiries, and present how patients minimise their claim to know and show that they do not consider themselves as entitled to state a goal. The final section includes examples of how participants collaboratively manage goal-setting.

1. Open questions to initiate goal-setting - The questions formulated by physiotherapists to topicalise goal-setting are all similar in the format. All of them use the term "expectations" as a way to enquire about goals. The extract below is an example of this. Please refer to Appendix 1 for transcription convention.
In this example, the physiotherapist specifies "expectation", (line 7) by adding "with regard to your knees" (line 8). As the response is not forthcoming (pause of 1.1 second - line 9), the physiotherapist starts to speak again by joking about the question ("it is quite a question isn't it?" - line 10). Laughter following a non-response is one way to indicate troubled communication [27]. Through this move the physiotherapist relieves the pressure for the patient to respond to the question.

The examples shown here demonstrate that goal-setting is treated as a topic in its own right and that the question assumes the patient possesses knowledge about goals/expectations for physiotherapy. Physiotherapists orient to the difficulty of the question but nevertheless pursue a response to the question.

As a general rule we find that:

(1) Goal setting is initiated after the prior topic has been brought to an end.

(2) In most cases, physiotherapists use possessives (e.g. "your goals") indicating that goals are "intrinsic" features of patients.

(3) As "expectations' can mean different things to patients, physiotherapists specify that these expectations are sought with regard to therapy (Extract 1) or the physical problem for which the patient has been referred to their services (Extract 2).

(4) Physiotherapists pursue a response to the goal enquiry.

Having given examples of the way in which questions about goals are formulated, the next section shows how patients respond to these explicit goal enquiries. As Extract 2 above has already

\section{Extract 1: HO 03 PTu Rx1_8.07}

15 Physio .hh D'accord. alors (1.5) eh- quelles sont vo:s- vos attentes par rapport à la physio .hh Okay. well (1.5) uh- what are yo:ur- your expectations with regard to physio

In this extract, the physiotherapist treats goal-setting as a new topic unrelated to prior talk. This is evident in the way she closes the discussion with "Okay" and a 1.5 second pause before she enquires about the goal. This goal enquiry embeds the assumptions that the patient has knowledge about goals.

Extract 2 illustrates how goal-setting gets introduced (after discussion about medication) and how the previous topic is brought to an end before goal setting starts. This case is a patient who has recurrent knee pain but would like to be able to play badminton again. begun to show, responding is difficult for some patients.

2. Patients' responses to physiotherapists' goal enquiry: downgrading the response - In only three cases, straightforward responses are produced, whereas in the majority of cases $(8 / 11$ cases), there are interactional features which indicate patients' difficulty with the response. Due to the high number of troubled communication, we present initially various features of this difficulty. The patient in Extract 3 is referred to physiotherapy for her back and neck problems and does not have previous experience with physiotherapy.

Extract 2: HO 05 PTq Rx1_7.13

1 Patient Et puis (.) c'est [à longterme] j'ai arrêté le CalcoSufer

And then (.) it is [in the long run] that I stopped the CalcoSufer (name of a drug)

2 Physio [D'accord]

[Alright]

$3 \quad(\mathbf{0 . 3})$

4 Physio Okay donc là c'est e:::n diminution en fai[t.]

5 Patient [O]ui

$[\mathrm{O}] \mathrm{ui}$
$[\mathbf{Y}] \mathbf{e s}$

$6 \quad(\mathbf{0 . 7})$

7 Physio .hh D'accord. (.) et pu::::is en fait quelles sont vos attentes par rapport à la physio= .hh Alright (.) and the:::n actually what are your expectations with regard to physio=

$8 \quad=$ par rapport à vos genoux $=$ with regard to your knees

$9 \quad \mathbf{( 1 . 1 )}$

10 Physio Elle est chouette cette question hein? hehehe

11 It is quite a question isn't it? hehehe (1.4) 
Extract 3: HO 07 PTu Rx1_12.05

\begin{tabular}{|c|c|}
\hline 1 Physio & $\begin{array}{l}>\text { Qu'es }=\text { ce vous }<\text { attendez de la physio? } \\
>\text { What is it you }<\text { expect from physio? }\end{array}$ \\
\hline 2 & $(1.8)$ \\
\hline 3 Patient & $\begin{array}{l}\text { Be:::[in] } \\
\text { We:::[ll] }\end{array}$ \\
\hline 4 Physio & $\begin{array}{l}\text { [Bonn]e questi[on.] } \\
\text { [Good] questi[on.] }\end{array}$ \\
\hline 5 Patient & $\begin{array}{l}[\mathrm{Je}] \text { n'ai jamais fait alors e:h- }[\mathrm{j}=\text { sais }] \text { pas à quoi ça } \mathrm{s}=\text { ressem[ble }] \\
{[\mathbf{I}] \text { have never done so } \mathbf{u}: \mathbf{h}-[\mathbf{I} \text { don't know }] \text { what it looks } \underline{\text { li }}[\mathbf{k e}]}\end{array}$ \\
\hline 6 Physio & $\begin{array}{l}{[\uparrow \mathrm{M}] \mathrm{hmhm}} \\
{[\uparrow \mathbf{M}] \mathbf{h m h m}}\end{array}$ \\
\hline 7 Patient & $\begin{array}{l}J=\text { pense que c'est des exerci:ces e::::[h-] } \\
\text { I think that there are exerci:ses u::::[h-] }\end{array}$ \\
\hline $\begin{array}{l}8 \text { Physio } \\
9\end{array}$ & 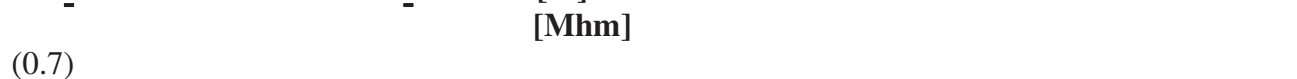 \\
\hline 10 Patient & Comment (.) ehh (.) porter un truc e:hh les positions qu'il faut faire mais- \\
\hline & $\begin{array}{l}\text { Like (.) uhh (.) carrying a thing u:hh the positions that one should do but- } \\
(\mathbf{0 . 5 )}((\text { physiotherapist starts writing in her chart }))\end{array}$ \\
\hline 2 Physio & Mhm \\
\hline
\end{tabular}

In Extract 3, the difficulty to respond is illustrated by the use of "well" ("bein" - line 3) and the prolonged pause (line 2-1.8 seconds) indicating hesitation [28]. The physiotherapist acknowledges this difficulty by referring to the question as not an easy one. The patient then provides a reason for her lack of knowledge (line 5 - "I have never done so u:h-I don't know what it looks like"). She makes a "good guess" about what she thinks physiotherapy could be like (exercises - line 7; positions - line 10). Well-prefaced responses to $w h$-questions have been described to indicate communication problem [29]. In the majority of the cases in our data, a delayed response is associated with the wellpreface which is in line with prior research [30] and which is described as breaking the flow of communication [29]. This interruption of the flow is, as our example shows, due to the physiotherapist's assumption that the patient should know about goals, yet the patient shows lack of this knowledge. This tension is played out in the patient's response by using hesitation markers (well, prolonged pause) and the use of "I think" which indicates that the patient does not treat herself as entitled to know.

Patients' responses to goal enquiries shed light on how knowledge is treated in physiotherapy consultations. In general, speakers are careful about making claims when they suspect that co-participants have better knowledge of some state of affairs
[31]. In order to moderating their knowledge claim speakers may use specific communication "tools" (e.g. well-prefacing). When speakers with more in-depth knowledge talk, they usually have primary rights to knowledge in this specific domain [32]. In addition to this, using expressions such as "I think", indicate uncertainty or limited entitlement about what has just been said.

We were able to show how participants in physiotherapy manage the knowledge with regard to goals during the consultation. The communication may become problematic, when physiotherapists' questions assume that patients know something (i.e. their goal), and the patient either does not have this knowledge, or they do not treat the conversation as one in which it is appropriate for them to report their knowledge.

3. Collaborative goal-setting - Using delayed onset ("well') and "I think" are ways in which patients indicate uncertainty about the claim they make about their goal. The next example shows that in instances where the patient has difficulty stating a goal, the physiotherapist manages this by proposing a goal which can then be accepted by the patient.

The patient in Extract 4 is consulting the physiotherapist for her chronic back pain. She has previously had physiotherapy and has been specifically referred to pool therapy.

\section{Extract 4: HO 03 PTu Rx1_8.07}

1 Physio .hh D'accord. alors (1.5) eh- quelles sont vo:s- vos attentes par rapport à la physio

2

3 Patient Bon je [pense que ça peut m:e- comment (

Well I [think that it can m:e- how ( [( )]

4 Physio

5 Patient

=pas me détendre mais m'assouplir $=$ not

6

7 Patient

(0.9)

8 Physio

e pense que c'e[st tout-

I think that it [is all-]

[Tout-] tout coincé

[All-] all stuck

9 Patient

Ah oui voilà

ça doit être to:ut tout coincé et tout eh:: (.) tout raide quoi

10 Physio

\section{) eh:: (.) comment on dit ça=}

) uh:: (.) how do you say it=
Oh yes that's it it has to be a:ll all stuck and all uh::(.) all stiff huh

D'accord okay

Alright okay

un peu ma::is- (.) je pense que c'est tout eh::-

a bit bu::t- (.) I think that it is all uh:::- 
After the goal enquiry there is a longer pause (line 2) followed by a hedged response ("well" - line 3) and an explicit search to find the right words ("how do you say" - line 3). The patient gets help from the physiotherapist who finishes the patient's description of what the problem is ("all stuck" - line 8). This problem proposal is accepted by the patient (line 9) and the physiotherapist brings this topic to an end (line 10). This example shows that participants manage goal-setting in an interactive, collaborative way. However, in this case that the patient does not treat herself as entitled to state a goal, an asymmetry of knowledge between participants comes to surface.

In the next example, the patient responds in quite a straightforward manner. Even though it is a case with a less problematic communication, the patient still uses a well-prefaced response to state her goal. The patient has been referred to physiotherapy after a skiing accident that left her with a sprained ankle. and (b) knowledge about the possibilities of physiotherapy and what it can achieve.

\section{Discussion}

Goal-setting is not simply a matter of physiotherapists enquiring about goals and patients responding to the question. Participants relate to each other in terms of what type of knowledge they are entitled to have, and with what degree of certainty they treat their knowledge claim. We have presented cases in which physiotherapists initiate goal-setting using an open question like "what do you expect from physiotherapy?', and show that those exchanges are frequently less than straightforward. Physiotherapists in our sample use questions implying that goals are an independent entity and assumptions are embedded in the goal enquiry with regard to access to knowledge. Physiotherapists assume that

\section{Extract 5: HO 13 PTt Rx1_24.11}

The physiotherapist just finished the muscle testing and continues to palpate the structures around the ankle. There is a long silence with the physiotherapist concentrating on her activity and the patient observing the physiotherapist.

1 Physio .hh Alors vous- que- quelles seraient vos attentes par rapport à ces- ces=

$2 \quad=$ séances de physio eh- (.) qu'on va faire ensemble

$=$ physio sessions uh- (.) that we will do together

$3 \quad(0.8)$

4 Patient e:h Bein pouvoir récupérer la- la mobilité du pied parc=que ça me gène

u:h Well to be able to recuperate the- the mobility of the foot because it bothers me

5 vous dites que je ne bouge pas mal mais par rapport à l'autre je [sens que] ça bloque

6 Physio you say that I do not move badly but in comparison to the other I [feel that] it blocks

7 Physio Oui oui tout à fait

[Mhm]

Yes yes absolutely

The physiotherapist initiates the enquiry about goals by asking the patient about her expectations (line 1 - "what would be your expectations with regard to those physio sessions"'). It is interesting to note that the physiotherapist emphasises the collaborative aspect by bringing both participants into the equation, emphasising "together" ("that we will do together", - line 2). The patient formulates her goal in a straightforward manner "to be able to recuperate the mobility of the foot' (line 4), but she adds a justification that challenges the physiotherapist's previous assessment. The patient insists on the restricted movement ("it blocks" - line 5) even though the physiotherapist assessed the mobility as good. The patient's emphasis on her own perception ("I feel" - line 5) gives her the necessary entitlement of her claim which is subsequently accepted by the physiotherapist (line 7 - "Yes yes absolutely").

Our analysis has shown that goal setting is not always as straightforward as policy guidelines seem to assume. In 11/37 cases in our corpus, an explicit enquiry about goals is initiated by the physiotherapists using a format such as "what do you expect from physiotherapy?" The responses are often delayed and wellprefaced. Patients indicate with their ways of responding that they do not treat themselves as entitled to know, and provide accounts to explain their "no-knowledge" response. We were able to show how patients manage in a subtle way the tug-of-war between co-operating by responding to a question while, at the same time, conveying some asymmetry in knowledge with regards to goals (Extract 4). In addition, participants need to find a balance between the different types of knowledge: (a) knowledge of their own body possessed by the patient versus physiotherapy knowledge owned by the physiotherapist; patients have goals and that they are able to articulate them. Patients respond to the enquiry by using well-prefacing and " $I$ think" to moderate their claim about knowledge. A delicate attention to what patients and physiotherapists know or are expected to know shows that participants manage during this process the patients' knowledge related to their body and the professionals' knowledge about bodies in general [33].

When assumptions between physiotherapists and patients are compatible, the communication can be considered smooth ("epistemically congruent") [34,35], and patients present goals without hesitations which does only rarely occur in our data. When those assumptions are not shared between participants, resources such as well-prefaces and "I think" are used to modulate their claim of knowledge and indicate that attention is paid to the physiotherapists' professional knowledge. Patients treat the goals as though it were not part of their domain, even though they have knowledge about their body and their physical abilities.

There is a growing body of evidence from analysis of healthcare communications confirming that asymmetry persists in physician's practice [36], as well as in other health care contexts such as genetic counselling [37], health visiting [38], pharmacy [16], speech and language therapy [18], and physiotherapy [9]. Asymmetries between patients and health care providers, however, are usually seen as problematic. In order to promote a partnership, patient-centred approaches are endorsed both in research and in clinical guidelines. "Shared decision making" [39] and "patient-centred medicine" [40] are omnipresent in today's health care communication. Yet, our results indicate that this partnership is not a discrete activity but 
something that has to be managed on an on-going basis involving claims of entitlement and knowledge about goals. Those social reasons might explain the limitation of patient involvement in goal setting detected in several studies $[8,41]$.

We should also be aware that this orientation to not being entitled to claim knowledge does not necessarily mean that patients do not possess the required knowledge. Ariss [42] points out that at times knowledge can be discussed in medical consultations with authority by patients with little actual knowledge while at other times a patient might possess knowledge without claiming authority with respect to that knowledge. Therefore, claiming knowledge is different from "knowing". Claiming less knowledge provides a way for patients to manage the delicacy of the interaction. Paying attention to the distribution of knowledge can yield to an increased understanding of lay-professional communication.

Some limitations of this study must be noted. First of all, linguistic resources cannot be generalised without reflection. Most of the studies using Conversation Analysis in medical and health care settings come from English-speaking countries. There is limited evidence on French-speaking health care communication. Prior research has looked at German patientphysiotherapy interaction of goal setting [43] in which similar resources (such as well-prefacing and "I think") were used by patients, indicating that access to and entitlement of knowledge is relevant for the physiotherapy context. Second, the sample size was small. Only in 11 consultations, physiotherapists elicited goals explicitly. Even with a limited size our analysis shows the delicacy of the communication and provides insight into those not so straightforward cases.

This study has added to the small body of work using Conversation Analysis to examine physiotherapy. One advantage of this method is that by paying close attention to details of communication between participants, both the patients' as well as the professionals' participation can be analysed [44]. A research synthesis of qualitative studies about patient participation concludes that goal setting is seen as a key moment to involve patients during consultations [45]. Professional practice could, therefore, also benefit from the findings of this paper. It has been argued that the conversation analytic approach to examining professional practice can help to adjust or correct existing professional theories by elucidating the ways in which they do (or do not) work in practice [46]. Our findings reveal that examining how participants respond to the question "what do you expect from physiotherapy?" opens up discussions about the distribution of knowledge between patients and clinicians that, to our knowledge, have never been attempted in physiotherapy before. It seems that blanket goal setting policies which treat goals as pre-set entities in patients' mind to be elicited are ill-fitted to the context of health care practice; they do not take into consideration concepts, such as if patients have the knowledge to state a goal and if they treat themselves entitled to do so, which are inherent to goal discussions. This non-consideration of social reasons might also be one of the possible reasons that evidence of the positive impact of goal setting is inconclusive [7]. Our findings suggest that explicit goal enquiry using an open question might not be the most appropriate communicative approach to goal setting. Future studies are needed to shed light on whether and how different approaches can overcome the difficulties identified here.

\section{Conclusion}

This study provides insight into goal-setting in physiotherapy and shows that assumptions are embedded in the goal enquiry questions presented about patients having a goal and their ability to present it. Responses to those enquiries are complex and patients respond to them by using well-prefacing and "I think", downgrading their claim of knowledge. The communication difficulties identified are related to the fact that it is assumed that the patient actually has the knowledge and understanding to be able to state an achievable and appropriate goal, and that the patient treats the physiotherapy consultation as one in which it is appropriate to claim knowledge of and preference for particular goals. While the first reason can be related to prior exposure/ experience with physiotherapy, the latter can be considered social reasons when patients do not make claims to their physiotherapist about what the goals should be. The findings show that patients convey their position in the ways that they respond to physiotherapists' questions. Results further indicate that patients sometimes attribute authority in the matter of goals to the physiotherapist, thereby contributing to persistent asymmetry during goal setting in physiotherapy.

\section{Acknowledgements}

We would like to thank all participants of the study as well as the head of the departments for giving opportunity to conduct this study. We are also grateful for the comments of the anonymous reviewers that help improve our paper.

\section{Declaration of interest}

This study was supported by the Do-RE funds from the Swiss National Science Foundation (No. 13DPD6_124565) and funds from RéSaR of the University of Applied Sciences, Western Switzerland, HES-SO. The authors report no conflict of interest.

\section{References}

1. Locke EA, Latham GP. Building a practically useful theory of goal setting and task motivation. Am Psychol 2002;57:705-17.

2. Scobbie L, Wyke S, Dixon D. Identifying and applying psychological theory to setting and achieving rehabilitation goals. Clin Rehabil 2009;23:321-33.

3. Physioswiss. Profil professionnel de la physiothérapie. Sursee: Swiss Physiotherapy Association; 2006.

4. Wade D. Goal setting in rehabilitation: an overview of what, why and how. Clin Rehabil 2009;23:291-5.

5. Bovend'Eerdt TJH, Botell RE, Wade, DT. Writing SMART rehabilitation goals and achieving goal attainment scaling: a practical guide. Clin Rehabil 2009;23:352-61.

6. Rosewilliam S, Roskell CA, Pandyan AD. A systematic review and synthesis of the quantitative and qualitative evidence behind patient-centred goal setting in stroke rehabilitation. Clin Rehabil 2011;25:501-14.

7. Levack WMM, Dean SG, Siegert RJ, McPherson KM. Navigating patient-centered goal setting in inpatient stroke rehabilitation: how clinicians control the process to meet perceived professional responsibilities. Patient Educ Couns 2011;85:206-13.

8. Sugavanam T, Mead G, Bulley C, et al. The effects and experiences of goal setting in stroke rehabilitation - a systematic review. Disabil Rehabil 2013;35:177-90.

9. Parry R. Communication during goal-setting in physiotherapy treatment sessions. Clin Rehabil 2004;18:668-82.

10. Barnard RA, Cruice MN, Playford ED. Strategies used in the pursuit of achievability during goal setting in rehabilitation. Qual Health Res 2010;20:239-50.

11. Heritage J. Questioning in medicine. In: Freed AF, Ehrlich S, eds. "Why do you ask?": the function of questions in institutional discourse. New York (NY): Oxford University Press; 2010:42-68.

12. Heritage J, Clayman S. Talk in action: interactions, identities and institutions. Chichester, UK: Wiley-Blackwell; 2010.

13. Clayman SE, Gill VT. Conversation analysis. In: Bryman HM, ed. Handbook of data analysis. London: Sage; 2004:589-606.

14. Barnes R. Conversation analysis: a practical resource in the health care setting. Med Educ 2005;39:113-15. 
15. Heritage J, Maynard DW. Communication in medical care: interaction between primary care physicians and patients. Cambridge: University Press; 2006.

16. Pilnick A. "Why didn't you just say that?": dealing with issues of asymmetry, knowledge and competence in the pharmacist/client encounter. Sociol Health Ill 1998;20:29-51.

17. Jones A. Creating history: documents and patient participation in nurse-patient interviews. Soc Health Ill 2009;31:907-23.

18. Denman A, Wilkinson, R. Applying conversation analysis to traumatic brain injury: investigating touching another person in everyday social interaction. Disabil Rehabil 2011;33:243-52.

19. Drew P, Chatwin J, Collins S. Conversation analysis: a method for research into interactions between patients and health-care. Health Expect 2001;4:58-70.

20. Parry R. Practitioners' accounts for treatment actions and recommendations in physiotherapy: when do they occur, how are they structured, what do they do? Soc Health Ill 2009;31:835-53.

21. Martin C. From other to self. Learning as interactional change [dissertation]. Sweden: University of Uppsala; 2004.

22. Ten Have P. Doing conversation analysis: a practical guide. London: Sage; 1999.

23. WMA (World Medical Association). Declaration of Helsinki ethical principles for medical research involving human subjects. 2008. Available from: http://www.wma.net/en/30publications/ 10policies/b3/index.html [last accessed 20 Feb 2013].

24. Heritage J. Conversation analysis and institutional talk: analysing data. In: Silverman D, ed. Qualitative research: theory, method and practice. London: Sage; 2004:222-45.

25. Heritage J. Conversation analysis and institutional talk. In: Fitch KL, Sanders RE, eds. Handbook of language and social interaction. Marwah (NJ): Lawrence Erlbaum; 2005:103-47.

26. Jefferson G. Glossary of transcript symbols with an introduction. In: Lerner GH, ed. Conversation analysis: studies from the first generation. Amsterdam/Philadelphia: John Benjamins; 2004:ix-xvi.

27. Hakaana M. Laughter in medical interaction: from quantification to analysis, and back. J Socioling 2002;6:207-35.

28. Schegloff EA. Sequence organization in interaction. Cambridge: University Press; 2007.

29. Schegloff EA, Lerner GH. Beginning to respond: well-prefaced responses to wh-questions. Res Lang Soc Interac 2009;42:91-115.

30. Goodwin C, Heritage J. Conversation analysis. Ann Rev Anthropol 1990;19:283-307.

31. Heritage J, Raymond G. The terms of agreement: indexing epistemic authority and subordination in assessment sequences. Soc Psychol Quart 2005;68:15-38.

32. Stivers T, Mondada L, Steensig J. Knowledge, morality and affiliation in social interaction. In: Stivers $\mathrm{T}$, Mondada L,
Steensig J, eds. The morality of knowledge in conversation. Cambridge: University Press; 2011:3-24.

33. Enfield NJ. Sources of asymmetry in human interaction: enchrony, status, knowledge and agency. In: Stivers T, Mondada L, Steensig J, eds. The morality of knowledge in conversation. Cambridge: University Press; 2011:285-312.

34. Hayano K. Claiming epistemic primacy: yo-marked assessments in Japanese. In: Stivers T, Mondada L, Steensig J, eds. The morality of knowledge in conversation. Cambridge: University Press; 2011:58-81.

35. Heinemann T, Lindström A, Steensig J. Addressing epistemic incongruence in question-answer sequences through the use of epistemic adverbs. In: Stivers T, Mondada L, Steensig J, eds. The morality of knowledge in conversation. Cambridge: University Press; 2011:107-30.

36. Peräkylä A. Agency and authority: extended responses to diagnostic statements in primary care encounters. Res Lang Soc Interac 2002; 35:219-47.

37. Pilnick A. "There are no rights and wrongs in these situations", identifying interactional difficulties in genetic counselling. Soc Health Ill 2002;24:66-88.

38. Heritage J, Sefi S. Dilemmas of advice: aspects of the delivery and reception of advice between health visitors and first time mothers. In: Drew P, Heritage J, eds. Talk at work: interaction in institutional settings. Cambridge: University Press; 1992:359-417.

39. Barry MJ, Edgman-Levitan S. Shared decision making - the pinnacle of patient-centered care. N Engl J Med 2012;366:780-1.

40. Little P, Everitt H, Williamson I, et al. Preferences of patients for patient-centred approach to consultation in primary care: observational study. BMJ 2001;322:486-72.

41. Leach E, Cornwell P, Fleming J, Haines T. Patient centered goalsetting in a subacute rehabilitation setting. Disabil Rehabil 2010;32: 1419-27.

42. Ariss S. Asymmetrical knowledge claims in general practice consultations with frequent attending patients: limitations and opportunities for patient participation. Soc Sci Med 2009;69: 908-19.

43. Schoeb V. "What do you expect from physiotherapy?": a conversation analytic approach to goal setting in physiotherapy [dissertation]. UK: University of Nottingham (unpublished).

44. Collins S, Britten N, Ruusuvuori J, Thompson A. Patient participation in health care consultations: qualitative perspectives. McGraw Hill: Open University Press; 2007.

45. Schoeb V, Burge E. Perceptions of patients and physiotherapists on patient participation: a narrative synthesis of qualitative studies. Physiother Res Int 2012;17:80-91.

46. Peräkylä A, Vehviläinen S. Conversation analysis and the professional stocks of interactional knowledge. Discourse Soc 2003;14: $727-50$.

Appendix 1: Jefferson's transcription conventions [26].

\begin{tabular}{ll} 
Symbols & \multicolumn{1}{c}{ Explanation } \\
\hline[] & Indicates the point where overlap begins and ends \\
$(0.0)$ & Indicates elapsed time in silence in tenths of a second either within or between utterances \\
$()$. & Indicates a gap of less than 0.1 second \\
$\uparrow$ & Arrow up indicates a rising shift in intonation prior to the word \\
$\downarrow$ & Arrow down indicates a falling shift in intonation prior to the word \\
- & Horizontal dash indicates that the word sounds abruptly "cut off"' \\
$:$ & Indicates quieter passage of talk compared to the surrounding talk \\
$:$ & Indicates an extension of the syllable it follows \\
$=$ & Indicates that there is no interval between two utterances \\
() & Indicates that the transcriptionist is not able to hear the utterance \\
$(())$ & Indicates a description of a phenomenon (e.g. laughter, noise...) \\
\hline
\end{tabular}

